\title{
Library Resilience and Leadership in a Global Crisis
}

\section{Najmeh Shaghaei}

University of Southern Denmark, Odense, Denmark

nas@bib.sdu.dk, orcid.org/0000-0002-7884-8576

\section{Claire Knowles}

Head of Research Support and Digital Libraries, University of Leeds, Leeds, United Kingdom

C.Knowles1@leeds.ac.uk, orcid.org/0000-0002-6969-7382

\section{Fiona Morley}

Head of Digital Programmes and Information Systems, Maynooth University, Maynooth, Ireland

Fiona.Morley@mu.ie, orcid.org/0000-0002-2435-8192

\section{Alexandra Eveleigh}

Collections Information Manager, Wellcome Collection, United Kingdom A.Eveleigh@wellcome.org, orcid.org/0000-0001-8487-3420

\section{Núria Casaldàliga}

Servei de Biblioteques, Universitat Autonoma de Barcelona, Bellaterra, Spain Nuria.Casaldaliga@uab.cat, orcid.org/0000-0001-5954-7375

\section{Emma Nolin}

Head of Information Resources and Scholarly Publishing, Malmö University Library, Sweden emma.nolin@mau.se, orcid.org/0000-0003-0705-7635 


\title{
Andrea Tatai
}

Deputy Director of the University Library, Freie Universität, Berlin, Germany tatai@ub.fu-berlin.de, orcid.org/0000-0002-9842-6493

\section{Marc Cohen}

Head of Library Resources and Collections, Queen Mary University of London, United Kingdom

m.j.cohen@qmul.ac.uk

\section{Martine Pronk}

Academic Services Manager, Utrecht University Library, Utrecht, Netherlands

m.c.e.m.pronk@uu.nl

\section{Elke Ghesquière}

Head of Libraries, KU Leuven, Belgium

elke.ghesquiere@kuleuven.be, orcid.org/0000-0003-2437-4747

\begin{abstract}
Research Libraries, like other organisations during the COVID-19 pandemic, have been facing difficult choices concerning which services to offer, whilst minimising risk to their staff, communities, and users. As the post COVID-19 era beckons, library leaders are urged to adapt flexible strategic plans that apply to every facet of library operation to ensure the organisations remain both safe and resilient in the future. This paper discusses leadership skills and practical techniques that can be applied to help build resilient libraries and deliver positive new change in the post-COVID-19 recovery period. Our findings indicate that leaders need to find ways to
\end{abstract}


realign library ambitions to this uncertain new operating environment. The focus should be directed to digitisation and supporting systems, as well as on sustainability and transformative services. These are a must for the future of libraries.

Keywords: Research libraries; resilience; leadership; COVID-19

\section{Introduction}

In March 2020, research libraries all over Europe - indeed across most of the world - were suddenly required to close their doors and suspend most or all of their on-site services. The rapid shift towards remote library leadership which immediately followed was observed keenly and with particular interest by the $5^{\text {th }}$ cohort of the LIBER ${ }^{1}$ Emerging Leaders' Programme. The programme's Action Learning sets, already well established by the online conference call, coupled with an active WhatsApp group, swung into action as an effective, pan-European peer support network: sharing practical tips on how best to maintain essential library services online, ideas for keeping colleagues connected and motivated, how to avoid mental exhaustion and adjust successfully to the new realities of everybody working from home.

As the immediate shock and anxiety of the onset of the pandemic started to subside, the group began to appreciate the enormity of some of the challenges we had faced in common (despite some significant variance between national and local COVID-19 regulations and crisis preparedness); challenges which for the most part we have successfully overcome. We presented two webinars for LIBER drawing on our own experiences and reflecting on how leadership skills and library ambitions might be adapted to meet the emergent new operating environment for European research libraries. These webinars and a follow-up survey circulated to attendees and previous Emerging Leaders' cohorts addressed both practical and strategic aspects of the response to the COVID-19 crisis and its ongoing impact.

The purpose of the paper is to identify how research library leaders might build resilience out of the COVID-19 crisis. Prior to presenting our method and results, we will present the literature that has inspired and qualified our work. 


\section{Literature Review}

The modern world has never before seen a pandemic situation quite like COVID-19 (Kuknor \& Bhattacharya, 2021). Therefore, the literature on the topic of leading research libraries during a pandemic is scarce and we did not find published empirical studies but rather opinion papers, blogs and guidelines regarding the situation of research libraries around the world since the outspread of COVID-19. Despite that fact, we are satisfied that there was plenty of relevant research on Leadership in time of crisis and in response to COVID-19 which demonstrated the knowledge and established the credibility of our work.

The speed and scope of COVID-19 forced organisations and leaders to rise to a series of sudden challenges: the crisis also offered new opportunities to demonstrate distributed leadership and to employ crisis management skills that could facilitate an effective response to the crisis and beyond (Boin et al., 2013).

In an uncertain situation like COVID-19, strong leadership skills are vital to illuminate the path forward. While much of the literature focuses on crisis management, other researchers and business consultants have emphasised the importance of leader behaviour in building and sustaining a diverse workforce during and post COVID-19 (Cox, 2001; Kuknor \& Bhattacharya, 2020).

To advocate for organisational significance, protect infrastructure and restore trust among teams, leaders need to adopt strategies and tactics which are not only effective immediately during the pandemic, but can also be transformative in the future.

In this context, Renjen (2020) has defined strategy development as a means of turning from the crisis of the pandemic towards the creation of new value and organisational significance. This requires clarity of thinking, communication and decision making, all of which are of utmost importance for senior executives and leaders seeking to inspire people within their organisations to make it through this crisis and to prepare for whatever may come.

Before elaborating further, it is important to clarify the existing literature on strategies, values, communication, staff management, and characteristics of a 
resilience thinking, which are particularly relevant to our research question so we can discover similar studies linked to our research topic.

\subsection{Strategies and Values}

In more ordinary times, a section on strategy would no doubt focus on the long term, on establishing a clear vision and plan of action for the library over a period of around 3 to 5 years. Strategic planning is something library leaders typically anticipate requiring both time and space: creating a conducive environment for review and reflection; planning ahead to create opportunities for consultation, communication and engagement; ensuring alignment between library strategy and that of the wider university or other governing body.

We are accustomed too, to think of strategy primarily in terms of its outputs and standard measures: typically, a hierarchy of policy and planning documents, carefully crafted objectives, and key performance indicators. Change, in this context, is generally incremental and gradual; progress is carefully monitored; success is structurally embedded.

In March 2020, the abrupt switch into rapid response mode in the face of a global health emergency initially seemed to cast out these leisurely notions of strategy altogether. Whole sections of our strategic planning documents and the associated KPIs were rendered suddenly inconsequential: who has the capacity to lead a collaborative revision of collections development policy when students are struggling to access basic texts? How relevant are the library user satisfaction survey results when the library study spaces are inaccessible?

But after many months of COVID-19 restrictions, it is evident that the pandemic will continue to impact for a considerable period to come on how our libraries can operate and the services we are able to deliver. And that consequently we cannot remain in crisis mode forever: we must begin again to think ahead and begin to realign library ambitions to this uncertain new operating environment. Strategic planning is of course not a concept alien to a crisis setting, in fact the English word 'strategy' derives directly from the ancient Greek word for a general, or the leader of an army. This definition of strategy as a process, the 'art of planning', needs to evolve quickly in 
response to the changing environment, enabling leaders to capitalise rather than capitulate to formidable challenges as they arise. So, can research library strategy respond flexibly and positively to the coronavirus crisis, and if so, how?

Michael Day (2020) highlights the British Library's approach to the pandemic in adopting a digital-first strategy. The Digital Preservation team adapted their training approach from on-site to online delivery with recorded options available and found that this boosted attendance as well as generated more specific digital preservation queries from attendees. The pandemic served to highlight the growing importance of digital collections in supporting innovation in use, research and outreach.

Wheatley and Hervieux (2019) note that libraries have been reluctant to change and embrace new technologies such as AI, often waiting for a particular technology to reach market saturation before reacting. They argue that this approach needs to be revisited, libraries need to proactively seek out new technologies that may enhance the service and they need to initiate conversations by including developments such as AI in strategic plans. 'The AI revolution is not on the horizon; it is already here, and libraries need to make peace with this fact and begin the process of co-existence.'

\subsection{Communication}

With a strong set of communication strategies, organisations can focus on executing the actions that lead to the greatest impact and move forward.

Schear and Young (2020) believe that solidarity, trust and confidence are a set of principles customised to reflect the organisation's values and are essential to shape the positioning of communication among teams. A follow-up study by Martin (2020) stressed all teams are dealing with some level of "information overload". To avoid feeling overwhelmed, leaders must focus on improving communication within their organisation which not only helps through the current situation but will also help to navigate the changed future that comes next.

In the context of leading research libraries specifically, Martin Shaw (2020) describes a variety of responses to the pandemic, playing to different 
institutions' strengths and often in collaboration with others such as scholarly societies, librarians, academics, and active social media users. He hopes that these new connections and collaborations will continue. Pionke (2020) in a call-to-action notes that libraries need to consider accessibility as part of the changes enforced by the pandemic. 'There is a need for creative thinking and outreach to support learning of all types of communities with a variety of different needs'.

\subsection{Hybrid Working and Flexible Work Arrangements}

It needs no further explanation that as a result of the pandemic, library staff was largely forced to work from home overnight.

Craft (2020) notes that the pandemic has forced libraries to make rapid changes that otherwise would have taken significant time and planning. As the pandemic was then a novel situation, a body of literature had not built up yet on the impact of this, so the author has examined the earlier literature on the move to remote working in library technical services. This literature highlights the challenges of isolation, socialisation, and work-life balance. The flexibility of both employer and employee is key.

It seems likely that the transition to a post-COVID reality will be gradual at best, depending on the measures and degree of vaccination, which may vary from country to country. In addition, it appears that not all work is as effective in an online environment as it is on site. Lund et al. (2020) indicate in their study 'The future of remote work' that there is a big difference between the 'theoretical maximum' and 'effective potential' of work: "[...] employers have found during the pandemic that although some tasks can be done remotely in a crisis, they are much more effectively done in person. These activities include coaching, counselling, and providing advice and feedback; building customer and colleague relationships; bringing new employees into a company; negotiating and making critical decisions; teaching and training; and work that benefits from collaboration, such as innovation, problemsolving, and creativity $[\ldots]^{\prime \prime}$.

Therefore, although during the pandemic it became apparent that many activities can be performed remotely, it is questionable whether this is always desirable. It is likely that library leaders will need to prepare for a form of 
hybrid working in which the nature of the work determines where, when and how it is performed.

Leaders face the question of what adjustments this will require from the workforce and leadership in their organisation. Remote work is more than just working elsewhere. Brannon et al. (2021), research support specialist at OCLC Research, emphasises in a webinar on the new model library, that it's about flexible work arrangements, which brings a much broader perspective than just focusing on remote working. It also requires possible adjustments in training and education of employees, a different organisational culture, a different way of managing and leadership style, attitude and behaviour of each employee and manager and new agreements on how to work. Additionally, one can ask which possible adjustments to the workplace itself, geared to the activities taking place on site, should be facilitated.

Hybrid working requires a reconsideration of what leadership skills are desired to lead teams successfully in a post-COVID reality. Many overviews have appeared of skills and the do's and don'ts of leading teams in a hybrid work situation (a.o. City National Bank, 2020; Keijser, 2020; Mahra, 2020; Pitstick, 2020). In summary, a number of similarities can be seen. The first is to agree on how to work as a team and on the expectations regarding the results of the team and individual employees. The second recommendation is to communicate openly and regularly, and to do so especially from a basis of trust and respect. Third: Create a sense of belonging. Everyone wants to feel they are respected, treated fairly, included within the group, and connected to the larger goals of the organisation. And finally, the advice to increase resilience through reinvention. New digital possibilities require new skills of employees but also of leaders to manage and shape the hybrid working environment.

\subsection{Staying Resilient}

In the Lucidea (2015) White paper note that 'Leaders who successfully manage change both reassure and inspire their teams - and individual contributors who navigate change build a professional confidence that allows them to thrive.'

The New Model Library is a project providing the OCLC research team an opportunity to engage with library leaders on the changes that the pandemic 
has enforced and how this might evolve over time. Silipigni Connaway (2020) notes that for many students, teachers, researchers and others, the pandemic forced them to move from being 'skilled digital visitors to unwilling digital residents.' The unwilling digital residents may have to permanently adapt to their changed environment, but how library leaders can support positive transformation in this regard needs to be discussed.

Similarly, Mehta and Wang (2020) in their case study note the challenges of the pandemic for both library staff and other university staff who were forced to switch suddenly to a remote working model. Correct setup in the home office and work-life balance were key issues as well as negative emotional feelings such as isolation, anxiety, uncertainty and stress. Engaging faculty and students with digital library services was a particular challenge and required innovations in delivery of, and education about, this content. Open Educational Resources also grew in significance. The authors believe that the use of digital library services will continue to grow exponentially. It is their view that 'the global pandemic has not and will not rattle the essential role of a university library that provides support for faculty and students who teach and learn on-campus or off-campus before, during, and after the global crisis.'

Greenhall (2020) explains the 'digital shift' as an umbrella term for the analogue-digital transition of many library services, operations, collections and audience interactions which forms part of Research Libraries UK (RLUK) strategy. This report considers the impact of the COVID-19 pandemic on this digital shift that had already been taking place. COVID-19 acted as a catalyst for the rollout of platforms to support remote working. "The crisis provided members with an opportunity: to work in new ways, to question established ways of working, and to challenge the perception of the library and its role within the institution' (p.12). There was a recognition of the need for renewed advocacy around digital collections and services. The lockdown-enforced closures further provided opportunities for libraries to enhance and promote its role as a home for training and skills development particularly via online learning. Any requirement to access physical spaces in order to access certain digital collections was exposed as a vulnerability. However, '[lack of physical access] provided the opportunity to challenge existing perceptions of the library, and to advocate for its digital resources and the continued, and enhanced, investment in these' (p.21). In terms of physical spaces, the report notes that the pandemic provides a real opportunity to re-evaluate how 
individual roles are undertaken and how these relate to the library building and physical spaces. Blending of physical and digital via hybrid services is expected to remain for the foreseeable future.

Markovic and Zettler (2020) consider how physical library spaces may need to be reconfigured as we learn to live with COVID-19. Good design can avoid pinch points, which would be helpful for future distancing measures; movable furniture and reconfigurable, flexible spaces also enable libraries to provide flexibility for future service changes.

For example, to make up for decreased capacity indoors, libraries might consider whether they can add safely arranged outdoor spaces to enable more people to connect to library services. Or over the medium to longer term, libraries might consider shifting their stock of computers to laptops that are distributed via a central kiosk. This would allow for more regular cleaning between users while also facilitating social distancing by allowing users to disperse themselves throughout the library (instead of being forced into large banks of desktops).

In summary, previous research has not given any conclusive answers to our research question of how research library leaders might build resilience out of the COVID-19 crisis. The closest we come to an answer is panel of Lucidea (2015) which indicates that resilient library leaders are visionary, innovative, strategic, proactive and networked and seek opportunities for positive change from unexpected and uncontrollable events, making their library indispensable to the organisation. Challenges must be seen as opportunities.

\section{Methods}

The study is qualitative in nature as the purpose was to investigate experiences, perceptions, and principles as put into action by library leaders during the pandemic and discuss what changes are likely to be here to stay.

In November 2020, the authors presented two webinars aimed at mid-level management teams at university libraries. The first was entitled "How are Research Libraries leading through COVID-19?" and addressed leadership 
skills in times of crisis and remote leadership challenges, for example how to realign library values and strategies to the new working environments. The second webinar was entitled "New challenges and leading into the postCOVID Recovery for Research Libraries". During this second webinar, the speakers shared their experiences communicating with teams and discussed how to create clarity, build resilience, and catalyse positive change. They also discussed new challenges likely to occur in the post-COVID Recovery period. Some questions highlighting multiple aspects were asked during the webinars. These questions, together with discussions from the Chat, fed into the research for this paper. Following the webinars, a survey in Jisc's Online Survey tool was circulated covering the themes discussed. This was circulated by e-mail to the attendees of the webinar, previous cohorts of the LIBER Emerging Leaders Programme and advertised on social media. We included a cover letter, which we drew up to state the purpose of the survey, together with the link where to find it online. The survey was completely anonymous and was open for a total of 21 days. For survey questions please see Appendix 1.

The number of respondents to the survey was not very high, with 24 submissions. However, as they were very open-ended questions, several significant ideas can be drawn from the responses. The survey was divided into four sections: communication, strategy, values and what to keep.

\section{Results and Analysis}

For the present study, the thematic survey method suggested by Braun and Clark (2006) was used to elicit knowledge and examine participants' perceptions, insights and experiences. Initial outcomes were generated by data analysis (Figure 1). The survey was used as a means of collecting information through responses that participants provide to the questions asked (see Appendix 1). Data gathered from the survey was analysed by four major themes. Outcomes emerged from the data to answer our research question, "how research library leaders might build resilience out of the COVID-19 crisis?".

We determined $84 \%$ of the attendees to both webinars had a leadership role in their library, and $16 \%$ were employed as a professional librarian. 
Fig. 1: Categorization and thematic analysis.

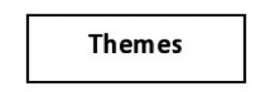

\section{Outcomes}

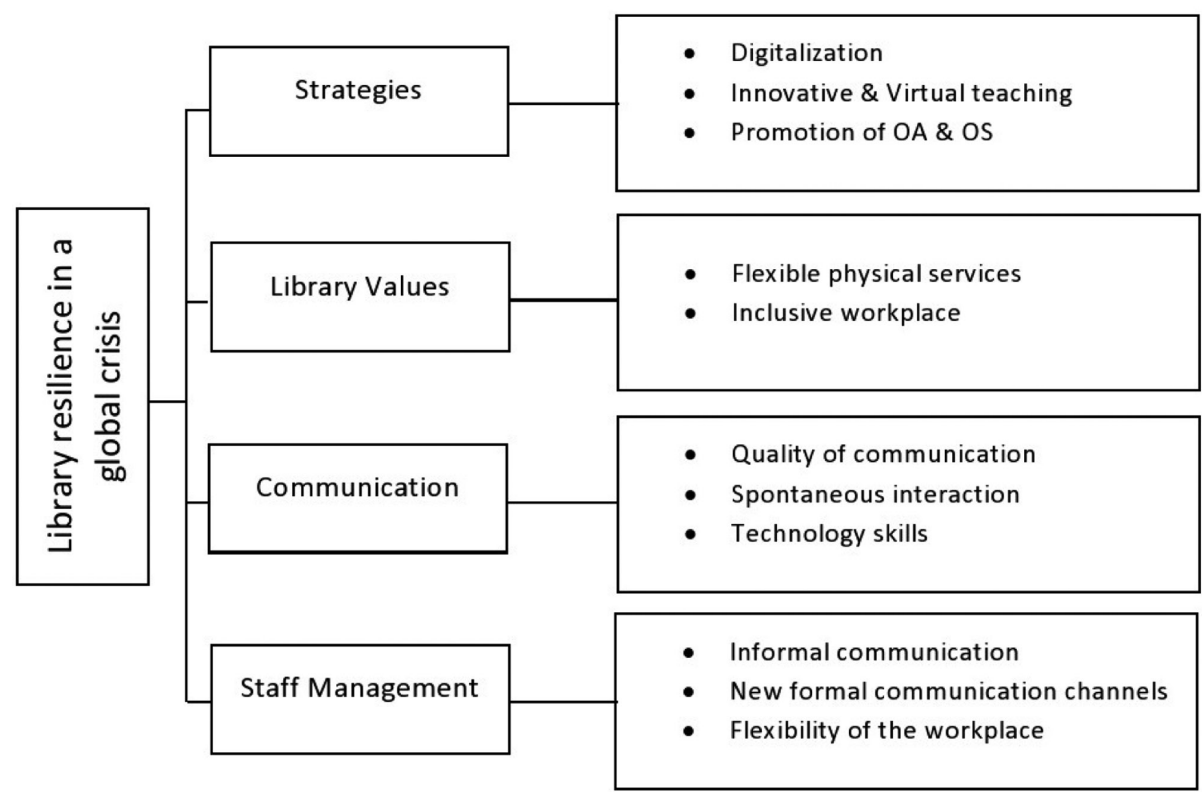

The most critical issues during the pandemic were, by far, management of uncertainty and constant change, as well as staff management. Effective communication was the third most difficult element.

\subsection{The Library's Strategic Goals are Still Broadly Relevant and Fit for Purpose}

91\% of respondents believed that the library's strategic objectives remained valid during the coronavirus crisis (Figure 2). $94 \%$ of the comments given in response to the question "Can you give one or more examples of how existing strategies influenced your research library's responses to the coronavirus crisis?" are examples of how the strategy that already existed in the library facilitated the response to coronavirus, while only $6 \%$ refer to a change in strategy or the establishment of a new one. 
Fig. 2: Are your library's strategic goals still broadly relevant and fit for purpose?

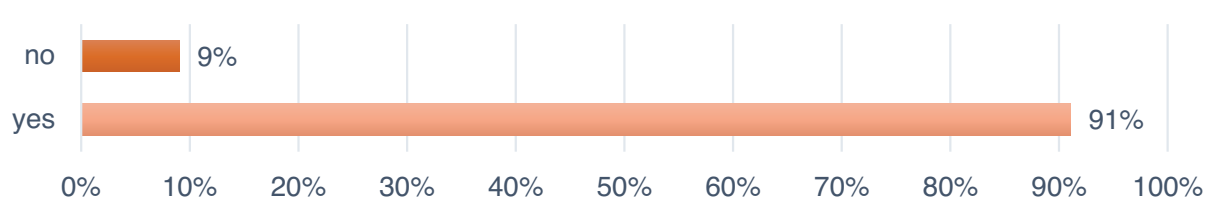

The high percentage of responses which offered examples of how existing strategies influenced the response to the coronavirus crisis may be mainly due to the fact that the pandemic has been the accelerator of trends and changes that research libraries had already initiated: a firm commitment to global reach and digital formats, a contribution to teaching innovation and virtual training, as well as the promotion of open access and open science in general.

$30 \%$ of the responses stated that different aspects of digitisation in their strategy correlated to the 'new normal' (Figure 3). Examples of the acceleration of this digitisation strategy are digital resources, more eBooks, digital innovations, digital services, scan \& deliver and digital shift.

Another strong area in existing library strategy was a user centered focus which was useful during the rapid development that needed to occur during the pandemic. Following these UX strategy goals libraries have expanded their services and, for example, provided new reservation systems for study places, computer loans, click-and-collect and postal loan.

Fig. 3: How did existing figures influence your research library's responses to the coronavirus crisis?
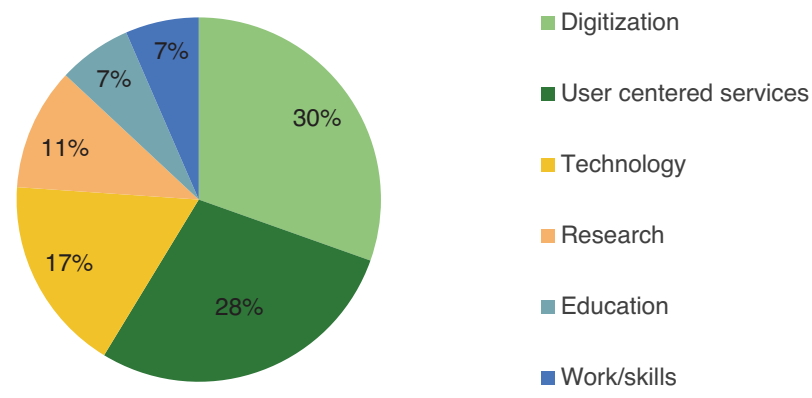
Some of these services have been possible due to the fact that libraries and/or universities previously have been investing in technology. For example, end users have remote access to the digital collections which make the electronic content accessible irrespective of time and place.

The movement towards Open Access and Open Knowledge within research are also in line with library strategies.

\subsection{The Library's Values are Promoted and Communicated through Library Strategy}

Respondents commented on how user-centered values are core libraries' strategies as demonstrated through the $70 \%$ of comments relating to these areas of social responsibility, collaboration and user-based (Figure 4).

\subsection{The Main Challenges and Advantages of using Online Tools to Communicate}

When we asked the leaders to describe library communication during the pandemic, 41\% described it with negative adjectives like: difficult, challenging, insufficient, overwhelming, chaotic, bad, erratic... which refers to the avalanche of information that existed during this time and the difficulty of conveying the right messages. The ones considered neutral express it as essential, critical, or very important. Finally, 22\% of the respondents highlighted the more personal side of communications such as caring, attentive, and carefully planned but also quick, better or improved.

Fig. 4: Values from the strategies that were challenged during the crisis?

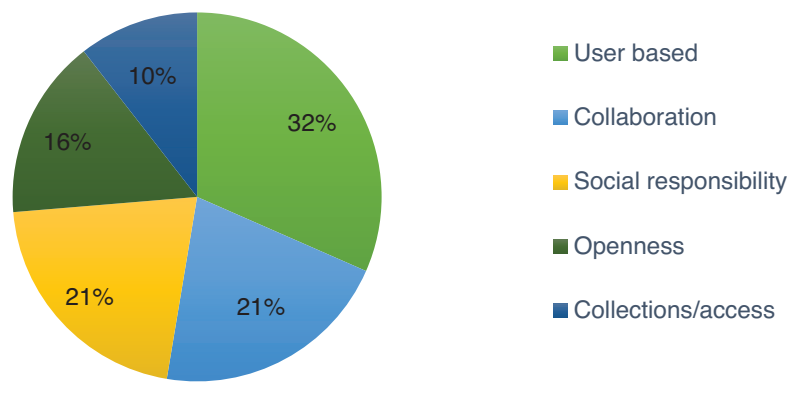


To the question "How have your team and co-workers maintained social communication during the pandemic?", many of the respondents expressed that they have continued to maintain social communication, and 95\% did so in digital format.

Respondents commented that the main challenge with using digital communication tools is the quality of communication (Figure 5). They relate this to not being able to interpret body language and non-verbal communication, which makes it easier to misunderstand, lose nuances, and makes it harder to find the right tone. Another difficulty is that there are no informal conversations or spontaneous interactions; this means that communication is more formal and needs to be planned. Moreover, there is a lack of continuity in the exchange of knowledge, and it is more difficult to bring the creative aspects to communication. The consequence is that you have to invest more time working, and that surviving multiple meetings taking place at once and being permanently connected is exhausting.

Another challenge evident in responses relating to the use of online platforms is the difficulty of staff acquiring the skills needed to use various tools, regardless of the technological problems that exist when the network crashes or Wi-Fi coverage is lost. Finally, from a leadership point of view, it can be more difficult to mediate conflicts and maintain the feeling of being a team.

The most notable advantages of using online communication tools are efficiency and accessibility. Efficiency is due to the absence of travel, which means that meetings can be scheduled one after the other. In addition, they are shorter, easier for everyone to attend, and can be recorded.

Fig. 5: Challenges of using online tools to communicate.
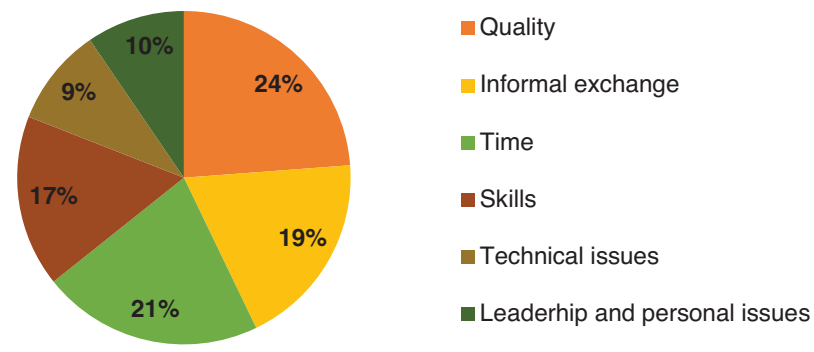
Challenges can also be opportunities: staff have improved their skills in the use of technological tools and applications, making libraries more digital. Also noteworthy is the number of seminars and conferences offered in digital format during the pandemic; there have been more opportunities for staff to acquire knowledge and at a lower financial cost.

During the pandemic it has been demonstrated that, apart from access to buildings or physical collections, the majority of the services offered by libraries can also be provided in digital format and sometimes it has been possible to reach a larger audience, as is the case with virtual training. Another different, but equally significant, option has been the ability to provide more personalised attention to users.

Finally, and from a leadership point of view, digital platforms have made communication from library management more inclusive and equitable.

\subsection{The Importance of Communication with Staff and Choosing the Best Option during the Pandemic}

In the responses to the question "Can you give one or more examples of techniques/methods you used to communicate with your staff during the pandemic crisis?" $70 \%$ of the comments referred to formal communication and $22 \%$ are informal communication. Besides, $8 \%$ refer to newly acquired habits.

Some examples of informal communication adopted by libraries are coffee via zoom, video lunches, informal mails, and a reading club.

In terms of formal communication, there is a clear predominance of online meetings and video conferencing, email is maintained as a tool for sending formal messages such as newsletters and weekly bulletins. Phone calls are also used, and among the answers there are some other formal tools like Slack, Team's planner, Jamboard and whiteboards.

Finally, the pandemic has been an opportunity to create new habits, such as sending empowering and encouraging messages and new cross-library groups have been created. 


\section{Conclusion}

In conclusion and as an answer to our research question, we found that the COVID-19 pandemic resulted in huge challenges for all organisations including research libraries. We identified some trends and impacts that have come out of the Coronavirus crisis that will be very important for research libraries going forward. Reflection on what has changed and what fundamentally remains the same may be the most important first step, to be followed by ongoing action which informs us how to transform our business model in the library for long term sustainability.

Flexibility of the workplace and working from home or another location outside the office is another aspect to be considered. Despite the possible negative effects (work-life balance, time management and increased stress), it seems to be something we are likely to maintain in the future, possibly as a hybrid model of on-site and remote working options. The fact that work in the "New Now" can take place anywhere and often at any time is perceived as positive. Aside from a flexible workplace, online meetings, virtual collaboration and consultation are changes worth keeping at some level.

To improve the gains from a more widespread "work from home" environment for productivity and innovation, the improved technical skills, which are a basis for mastering the new challenges in the job, are worth retaining. The crisis supported the ingenuity to move the social interaction into the digital realm, sometimes beyond what existed before the COVID-19 pandemic and with greater speed than may otherwise have been achieved.

Although the essential role of university and research libraries has not and will not change, the COVID-19 crisis made it clear how essential it is for the function of libraries to further expand digitisation initiatives. Expanding the range of digital resources, digital collaboration, whether in meetings or working together on projects, and virtual learning and teaching are digital changes that should be maintained in the post-pandemic world. Expanded openness, meaning both free access and accessibility, to teaching and learning content is also a positive outcome worth preserving. Furthermore, the possibility to access recorded events including training events and conferences regardless of time proved to be very positive and beneficial to many. The outline 
platform chat as a substitute or support for face-to-face contact should also be retained as a communication option.

Altered and flexible physical spaces, the appropriate administration and fit out of library spaces and workspaces should be maintained in the future. In addition, hygiene measures are mentioned particularly frequently in the literature. Thus, disinfectant dispensers may remain permanently in libraries into the future. Improved ventilation concepts also seem to be both necessary and sustainable. Technologies that enable self-service (e.g. book lending and return), postal lending, extended lending periods and online information instead of counter services are other aspects that are likely to remain after the pandemic.

The importance of space in the libraries becomes especially apparent when it is NOT available. The hygiene conditions to be maintained and social distancing to be observed make it clear how important it is to have ample space in libraries. The possibility of being able to book seats in the future, or to have an overview of the frequency of use, seems to be worth maintaining to avoid overcrowding, among other things. Equally important is the good and attractive fit out and layout of workplaces and rooms. In order to meet many requirements, a wide range of different rooms that can be flexibly zoned still seems to be one of the most important considerations of libraries as we move to a post-pandemic environment.

Finally, we are focusing on building resilient libraries. Regarding resilience theory, to manage the library successfully and build thoughtfulness, we should not ignore the changes happening around us. As library leaders we need to remain open to transformative change, to encourage and lead enhanced communications via multiple modalities and to be capable of building resilience within ourselves and within our teams both on-site and remotely. The library of the future is changing to an even more diverse and innovative place. Above all, the library should have room for the meaningful recognition of our intellectual values and be an adaptable place in terms of the physical environment and service provision in our "Brave New World".

\section{References}

Boin, A., Kuipers, S., \& Overdijk, W. (2013). Leadership in times of crisis: A framework for assessment. International Review of Public Administration, 18(1), 87-91. https://doi.org/10.1080/12294659.2013.10805241 
Brannon, B., Connaway, L. S., Simane, J., \& van der Werf, T. V. (2021). Eamearc 21 The New Model Library [Webinar Series]. OCLC. https://oclc.wistia.com/medias/ h4bwxev3qy

Braun, V., \& Clarke, V. (2006). Using thematic analysis in psychology. Qualitative Research in Psychology, 3(2), 77-101. https://doi.org/10.1191/1478088706qp063oa

City National Bank. (2020, January 20). 6 Key lessons for successful remote leadership. https://newsroom.cnb.com/en/business/leadership/remote-leadership.html

Connaway, L. S. (2020, July 30). The New Model Library. Welcome home. OCLC. https://blog.oclc.org/next/the-new-model-library-welcome-home/

Cox Jr, T. (Ed.). (2001). Creating the multicultural organization: A strategy for capturing the power of diversity. Jossey-Bass.

Craft, A. R. (2020). Remote work in library technical services: Connecting historical perspectives to realities of the developing COVID-19 pandemic. Serials Review, 46(3), 227-231. https://doi.org/10.1080/00987913.2020.1806658

Day, M. (2020, November 4). "We never closed." Digital continuity at the British Library during the pandemic. Digital Preservation Coalition, https://www.dpconline. org/blog/wdpd/blog-michael-day-wdpd

Greenhall, M. (2020). Covid-19 and the digital shift in action report. RLUK Report. https://www.rluk.ac.uk/covid-19-and-the-digital-shift-in-action/

Keijser, P. (2019, August 27). Remote leadership: How to lead your team from a distance. Business2Community. https://www.business2community.com/leadership/ remote-leadership-how-to-lead-your-team-from-a-distance-02233959

Kuknor, S. C., \& Bhattacharya, S. (2020). Inclusive leadership: new age leadership to foster organizational inclusion. European Journal of Training and Development. Advance online publication. https:// doi.org/10.1108/EJTD-07-2019-0132

Kuknor, S. C., \& Bhattacharya, S. (2021). Organizational inclusion and leadership in times of global crisis. Australasian Accounting Business and Finance Journal, 15(1), 93-112. http://dx.doi.org/10.14453/aabfj.v15i1.7

Lucidea. (2015). Building the resilient library. How (and why) to leverage change and become indispensable. https:/ / 2cwcr12ffoct2lm8t434p828-wpengine.netdna-ssl.com/ wp-content/uploads/2017/02/Lucidea-WP-Building-the-Resilient-Library.pdf

Lund, S., Madgavkar, A., Manyika, J., \& Smit, S. (2020, November 23). What's next for remote work: An analysis of 2,000 tasks, 800 jobs and 9 countries, McKinsey \& Company. https://www.mckinsey.com/featured-insights/future-of-work/ whats-next-for-remote-work-an-analysis-of-2000-tasks-800-jobs-and-nine-countries

Mahra, D. (2020, December 31). 12 Best Practices for Effectively Managing Remote Teams. ReveChat. https://www.revechat.com/blog/12-best-practices-effectively-managingremote-teams/ 
Markovic, A., \& Zettler, Z. (2020, May 12). Designing resilient libraries for a postcovid world. Building Design + Construction. https://www.bdcnetwork.com/blog/ designing-resilient-libraries-post-covid-world

Martin, S. (2020, December 14). Communicating in a Crisis: What, When, and How. Center for Creative Leadership. https://www.ccl.org/articles/ leading-effectively-articles/communicating-in-a-crisis-what-when-and-how /

Mehta, D., \& Wang, X. (2020). COVID-19 and digital library services - a case study of a university library. Digital Library Perspectives, 36(4), 351-363. https://doi.org/10.1108/DLP-05-2020-0030

Pionke, J. J. (2020). COVID-19, accessibility, and libraries. College \& Research Libraries News, 81(8), 398-399. https://doi.org/10.5860/crln.81.8.398

Pitstick, H. (2020, September 29). 4 Key leadership skills for a post COVID19 workplace. Financial Management. https://www.fm-magazine.com/news/2020/sep/ leadership-skills-for-post-coronavirus-workplace.html

Renjen, P. (2020, March 16). The heart of resilient leadership: Responding to COVID19. Deloitte Insights. https://www2.deloitte.com/us/en/insights/economy/covid19/heart-of-resilient-leadership-responding-to-covid-19.html

Schear, M., \& Young, D. (2020, May 8). Communicating leadership during COVID-19. BCG. https://www.bcg.com/publications/2020/communication-leadership-during$\underline{\text { covid-19 }}$

Shaw, M. (2020, July 1). The untold story of university libraries in lockdown. Wonkhe. https://wonkhe.com/blogs/the-untold-story-of-university-libraries-in-lockdown

Wheatley, A., \& Hervieux, S. (2019). Artificial intelligence in academic libraries: An environmental scan. Information Services $\mathcal{E}$ Use, 39(4), 347-356. https://doi. org/10.3233/ISU-190065

\section{Appendix 1: Liber ELP Leadership Webinar Survey}

Please help us understand more about how the COVID-19 pandemic has impacted your library leadership team's current and future plans, strategies and values:

\section{Communication}

1. What are the main challenges and advantages of using online tools to communicate? 
2. Can you give one or more examples of techniques/methods you used to communicate with your staff during the pandemic crisis?

\section{Strategy}

3. Are your library's strategic goals still broadly relevant and fit for purpose?

$X$ Yes

$X$ No

$X$ Don't know

If not, why not?

4. Can you give one or more examples of how existing strategies influenced your research library's responses to the coronavirus crisis?

\section{Values}

5. Can you give one or more examples of how your library's values are promoted and communicated through library strategy?

6. Can you also give one or more examples of how the crisis challenged the library's strategies in upholding some of these values?

\section{What to keep from COVID-19 changes?}

7. What two or three Covid-19 changes would you like to keep related to staff/human resources in the library?

8. What two or three Covid-19 changes would you like to keep related to digital in the library?

9. What two or three Covid-19 changes would you like to keep related to physical spaces in the library?

\section{Note}

\footnotetext{
${ }^{1}$ LIBER - The Association of European Research Libraries https://libereurope.eu/.
} 